07

\title{
Резистивное переключение в структурах металл-оксид-полупроводник с наноостровками GeSi на подложке кремния
}

\author{
(C) С.В. Тихов, В.Г. Шенгуров, С.А. Денисов, И.Н. Антонов, А.В. Круглов, А.И. Белов, Д.О. Филатов, \\ О.Н. Горшков, А.Н. Михайлов
}

Нижегородский государственный университет им. Н.И. Лобачевского, 603950 Нижний Новгород, Россия

e-mail: tikhov@phys.unn.ru

Поступило в Редакцию 9 августа 2019 г.

В окончательной редакции 12 марта 2020 г.

Принято к публикации 3 апреля 2020 г.

Показано, что самоформирующиеся наноостровки $\mathrm{GeSi}$, встроенные на границе раздела диэлектрик-полупроводник в структурах металл-оксид-полупроводник (МОП) на основе $\mathrm{Si}(001)$ с диэлектрическими слоями $\mathrm{SiO}_{x}$ и $\mathrm{ZrO}_{2}(\mathrm{Y})$, полученными магнетронным напылением, инициируют биполярное резистивное переключение без предварительной электроформовки. Исследованы вольт-амперные характеристики и электрофизические параметры МОП-структур в высокоомном и низкоомном состояниях. Установлено изменение встроенного заряда в диэлектрике вблизи границы раздела диэлектрик-полупроводник при резистивном переключении, связанное с формированием и разрушением проводящих филаментов. Наблюдалось стимулированное оптическим излучением переключение МОП-структур с диэлектрическим слоем $\mathrm{ZrO}_{2}(\mathrm{Y})$ из высокоомного в низкоомное состояние, связанное с увеличением проводимости области пространственного заряда в подложке $\mathrm{Si}$ вследствие межзонного оптического поглощения в $\mathrm{Si}$, что вызывает перераспределение напряжения между $\mathrm{Si}$ и $\mathrm{ZrO}_{2}(\mathrm{Y})$. Обнаружено различие в форме спектров малосигнальной фото-ЭДС МОП-структур в спектральной области собственной фоточувствительности $\mathrm{Si}$ в высокоомном и низкоомном состояниях, связанное с утечкой фотовозбужденных носителей заряда из $\mathrm{Si}$ в металлический электрод через филаменты.

Ключевые слова: мемристор, МОП-структура, резистивное переключение, электрофизические свойства, фоточувствительность.

DOI: 10.21883/JTF.2020.10.49808.300-19

\section{Введение}

Явление резистивного переключения (РП) в структурах „металл-оксид-металл“ (МОМ) и „металл-оксид-полупроводник“ (МОП) может быть использовано для создания нового поколения вычислительных систем, в том числе систем, моделирующих работу мозга, с малыми затратами энергии и большим быстродействием [1,2]. МОП-структуры, в которых проявляется эффект РП (мемристивный эффект), исследованы значительно меньше, чем МОМ-структуры (традиционные мемристоры). Однако мемристоры на основе МОП-структур проявляют фоточувствительность [3], и при использовании МОП-структур значительно расширяются возможности для изучения механизма электроформовки и РП [4,5].

Кроме того, дним из решающих недостатков, который не позволяет в настоящее время широко применять мемристоры, меняющие свое сопротивление в зависимости от величины и времени протекшего через них электрического заряда, является стохастическая природа РП, связанного с формированием и разрушением проводящих каналов (филаментов) в тонких оксидных пленках [6]. Причинами стохастичности могут быть многие факторы, перечисленные, например, в рабо- те [7]. Однако одним из решающих факторов является малое количество атомных/вакансионных (в случае оксидных мемристоров) цепочек, определяющих токонесущую способность проводящего филамента, структура которого случайным образом меняется от цикла к циклу переключения. На разброс параметров РП влияют случайное расположение и форма неровностей поверхностей электродов мемристивной структуры, которые служат концентраторами электрического поля в диэлектрике и приводят к возникновению проводящих филаментов в диэлектрике.

В работе [8] было обнаружено влияние наночастиц из $\mathrm{Au}$ на характеристики МОП-структур на Si. B настоящей работе впервые исследовано РП в МОП-структурах на $\mathrm{Si}$ с самоформирующимися наноостровками $\mathrm{GeSi} / \mathrm{Si}(001)$, которые выполняют функцию концентраторов электрического поля. Установлено также РП, стимулированное лазерным освещением.

\section{1. Методика эксперимента}

МОП-структуры изготавливались на пластинах монокристаллического $n-\mathrm{Si}(001)$ с удельным сопротивле- 
нием $0.005 \Omega \cdot \mathrm{cm}$. На этих пластинах на буферный слой $\mathrm{Si}$ толщиной $0.1 \mu \mathrm{m}$, выращенный методом молекулярно-лучевой эпитаксии (МЛЭ), методом газофазной эпитаксии (ГФЭ) из $\mathrm{GeH}_{4}$ при низком давлении $\left(9 \cdot 10^{-2} \mathrm{~Pa}\right)[9,10]$ при температуре $700^{\circ} \mathrm{C}$ формировался слой самоформирующихся (по механизму Странски-Крастанова) наноостровков $\mathrm{GeSi}$. Обычно такие островки используются для расширения спектральной области фоточувствительности $\mathrm{Si}$ фотодиодов в инфракрасную область [11].

На поверхность структуры, покрытую наноостровками $\mathrm{GeSi}$, осаждались пленки стабилизированного диоксида циркония (СДЦ) $\mathrm{ZrO}_{2}(\mathrm{Y})$. Осаждение проводилось методом высокочастотного магнетронного распыления в смеси $\mathrm{Ar}-\mathrm{O}_{2}(50: 50 \%)$ мишени, спеченной из смеси порошков $\mathrm{ZrO}_{2}$ и $\mathrm{Y}_{2} \mathrm{O}_{3}$ (12 mol.\%). Также исследовались МОП-структуры с диэлектрическими слоями $\mathrm{SiO}_{x}$, осажденными распылением кварцевой мишени в смеси $\mathrm{Ar}-\mathrm{O}_{2}(70: 30 \%)$. Температура подложки при нанесении диэлектриков была $300^{\circ} \mathrm{C}$. Толщина пленок СДЦ и $\mathrm{SiO}_{x}$ составляла $40 \mathrm{~nm}$. На поверхность диэлектриков методом магнетронного распыления на постоянном токе в Ar при температуре подложки $200{ }^{\circ} \mathrm{C}$ через маску с отверстиями наносились верхние электроды из Аu толщиной $20 \mathrm{~nm}$ с адгезионным подслоем $\mathrm{Zr}$ толщиной $3 \mathrm{~nm}$. Площадь МОП-структур $S$ составляла $\approx 10^{-3}$ или $10^{-2} \mathrm{~cm}^{2}$.

На полученных структурах измерялись вольт-амперные (BAX), вольтфарадные (ВФХ) и вольтсимменсные $(\mathrm{BCX})$ характеристики в интервале напряжений $0-10 \mathrm{~V}$ со скоростью развертки пилообразного напряжения $\beta \approx 0.25-0.003 \mathrm{~V} / \mathrm{s}$. ВФХ и ВСХ измерялись при амплитуде переменной составляющей $10 \mathrm{mV}$ в диапазоне частот $f=10^{3}-10^{6} \mathrm{~Hz}$. Знак пилообразного управляющего напряжения определялся потенциалом на верхнем электроде относительно подложки. Также измерялись малосигнальные характеристики мемристивных структур (при амплитуде переменной составляющей напряжения $10 \mathrm{mV}$ ) в параллельной и последовательной схемах замещения $[12,13]$ в диапазоне частот $f=10^{3}-10^{7} \mathrm{~Hz}$. В этом случае измерения характеристик проводились в исходном состоянии, после переключения в состояние с высоким сопротивлением (СВC) и состояние с низким сопротивлением (СНС). Определялись величины параллельной емкости $C_{p}$; параллельной проводимости, приведенной к круговой частоте $\omega, G_{p} / \omega$; параллельного сопротивления $R_{p}$; последовательного сопротивления $R_{s}$; тангенса угла диэлектрических потерь $\operatorname{tg} \delta$. Для температурных измерений образцы помещались в герметически закрытый металлический термостат с селикагелем, который мог нагреваться с помощью электронагревателя и охлаждаться погружением в жидкий азот. Измерения проводились в интервале температур 77-510 K в изотермическом режиме. Температура поддерживалась с точностью $1 \mathrm{~K}$. Все электрофизические измерения проводились на анализаторе полупроводников приборов Agilent B1500A.
Для исследования влияния оптического излучения на РП использовался лазерный диод (ЛД) марки LSR-660-1.5 с мощностью $1.5 \mathrm{~W}$ и длиной волны излучения $660 \mathrm{~nm}$. Плотность потока квантов лазерного излучения регулировалась с помощью набора нейтральных светофильтров в пределах $2.5 \cdot 10^{20}-6 \cdot 10^{21} \mathrm{~cm}^{-2} \mathrm{~s}^{-1}$. Этот же ЛД использовался для определения высоты поверхностного потенциального барьера в полупроводнике методом измерения барьерной фото-ЭДС насыщения [14]. Спектральная зависимость малосигнальной фото-ЭДС измерялась на частоте $70 \mathrm{~Hz}$ по стандартной методике с использованием монохроматора ИКС-12.

\section{2. Результаты и их обсуждение}

\section{1. Морфология поверхности и электрофизические свойства МОП-структур в исходном состоянии}

На рис. 1 приведено типичное изображение поверхности МОП-структуры с наноостровками $\mathrm{GeSi}$, покрытыми слоем СДЦ, измеренное с помощью атомно-силового микроскопа (ACM). Практически такие же изображения были получены на МОП-структурах, в которых островки $\mathrm{GeSi}$ были покрыты слоем $\mathrm{SiO}_{x}$. Эти данные показывают, что рельеф поверхности пленок диэлектриков и металла огибает рельеф поверхности наноостровков GeSi. Анализ поверхности структур позволил различить крупные кластеры $\mathrm{GeSi}$ (с высотой $\sim 100 \mathrm{~nm}$, размером у основания $\sim 300 \mathrm{~nm}$ и плотностью $\sim 10^{8} \mathrm{~cm}^{-2}$ ) и более мелкие островки GeSi (с высотой $\sim 10 \mathrm{~nm}$, размером у основания $\sim 50 \mathrm{~nm}$ и плотностью $\left.\sim 10^{9} \mathrm{~cm}^{2}\right)$. Последние островки имели куполообразную форму, а первые пирамидальную с аспектным отношением $\sim 1: 2$ [9].

Следует отметить, что хотя морфология поверхности структур практически не зависела от материала диэлек-

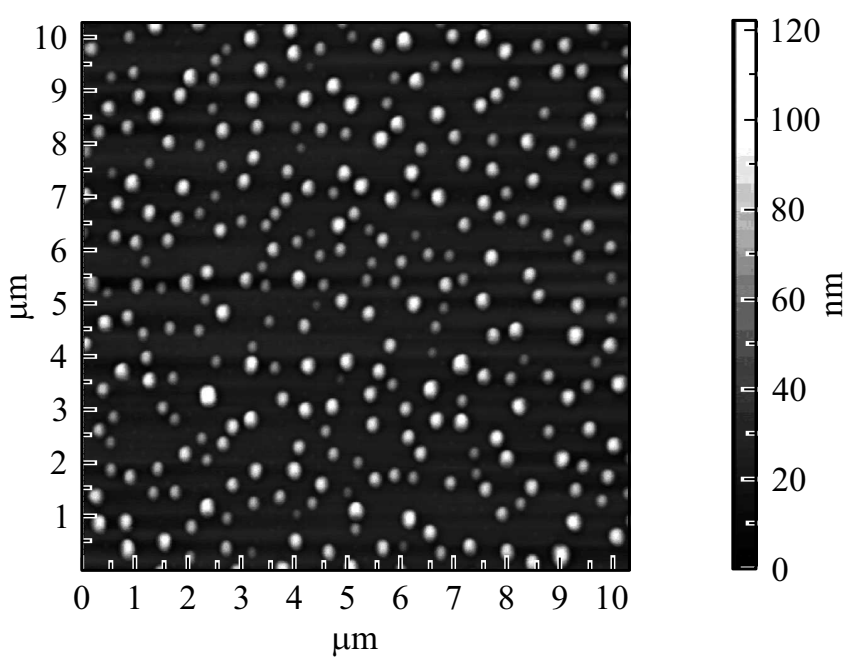

Рис. 1. АСМ-изображение гетероструктуры с поверхностными нанокластерами $\mathrm{GeSi} / \mathrm{Si}$, покрытыми слоем YSZ. 


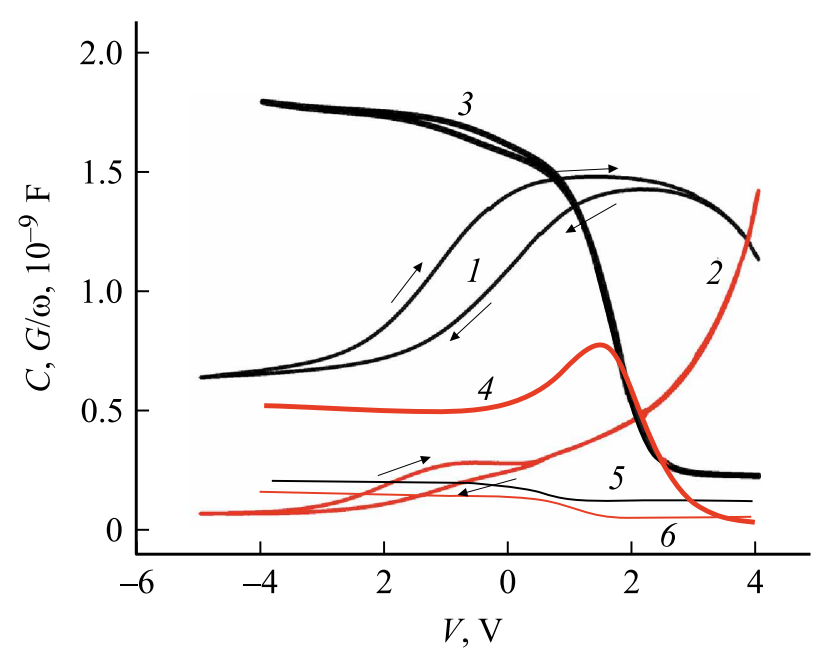

Рис. 2. Зависимости $C(1,3,5)$ и $G / \omega(2,4,6)$ от V. Кривые 1,2 - для МОП-структуры со слоем $\mathrm{SiO}_{x}$ на частоте $1 \mathrm{MHz}$, кривые 3,4 - для МОП-структуры со слоем СДЦ на частоте $1 \mathrm{kHz}$ и кривые 5, 6 - для МОП-структуры со слоем СДЦ на частоте $1 \mathrm{MHz}$.

трического слоя, электронные свойства границы раздела диэлектрик-полупроводник в МОП-структурах с оксидными слоями СДЦ и $\mathrm{SiO}_{x}$ существенно отличались. Вид ВФХ МОП-структуры со слоем СДЦ соответствовал p-типу проводимости полупроводника (рис. 2, кривые 3 и 5) [15]. Частотная дисперсия этих ВФХ связана с частотной дисперсией емкости диэлектрика. Даже на частоте $10^{3} \mathrm{~Hz}$ ВФХ сохраняла высокочастотный вид, не выявляющий электронного отклика. По кривой 3 был оценен безразмерный уровень легирования $\lambda p$-слоя, исходя из соотношений [15]:

$$
C_{I}=\frac{C_{\max }+C_{\min }}{C_{\max }-C_{\min }}, \quad C_{I}=\varepsilon_{0} \varepsilon_{s} / 2 L_{D} \lambda^{-1 / 2} \sqrt{2 \ln \lambda},
$$

в которых $C_{\max }-$ максимальная емкость на частоте $10 \mathrm{kHz}$ (принимается за емкость диэлектрика), $C_{\min }-$ минимальная емкость на частоте $10 \mathrm{kHz}$ (в области инверсии), $C_{I}$ - емкость инверсного слоя полупроводника, $\varepsilon_{0}-$ диэлектрическая проницаемость вакуума, $\varepsilon_{s}$ - относительная диэлектрическая проницаемость полупроводника, $L_{D}$ - длина Дебая в собственном $\mathrm{Si}$. По определению $\lambda=p_{0} / n_{i}$, где $p_{0}-$ равновесная концентрация дырок, а $n_{i}-$ концентрация собственных носителей в $\mathrm{Si}\left(1.4 \cdot 10^{10} \mathrm{~cm}^{-3}\right.$ при $\left.300 \mathrm{~K}\right)$, что дает значение $p_{0} \approx 10^{16} \mathrm{~cm}^{-3}$, которое согласуется со значением, определенным по наклону зависимости $1 / C^{2}$ от $V$ для обратно смещенного барьера $\mathrm{Au}(\mathrm{Zr}) / \mathrm{Si}$.

Поверхность полупроводниковой структуры под слоем $\mathrm{SiO}_{x}$ имела $\mathrm{n}$-тип проводимости (кривая 1 на рис. 2). Зависимость квадрата обратной неравновесной барьерной емкости от напряжения [16] дает профиль распределения концентрации равновесных электронов $n_{0}$, возрастающий от объема полупроводника к поверхности диэлектрика - от $5 \cdot 10^{16}$ до $5 \cdot 10^{17} \mathrm{~cm}^{-3}$ на расстоянии от 70 до $50 \mathrm{~nm}$ от границы раздела диэлектрик-полупроводник.

\section{2. Резистивное переключение в случае МОП-структур на основе $\mathrm{SiO}_{x}$}

На рис. 3 показаны типичные ВАХ исследованных МОП-структур со слоем $\mathrm{SiO}_{x}$, построенные в стандартной форме циклического биполярного РП между СНС (LRS) и CBC (HRS). Следует отметить, что представленные характеристики полностью соответствуют характеристикам РП анионного типа для аналогичных структур МОМ [17-19], с точностью до ряда качественных и количественных отличий (асимметрия и нелинейность ВАХ, другие значения напряжений переключения и т. д.), которые обусловлены вкладом полупроводниковой подложки и обсуждаются ниже для исследуемых МОП-структур.

Анализ участка BAX экспоненциального роста тока с напряжением при $V>0$ показал, что он лучше описывается формулой, соответствующей эффекту Пула-Френкеля [20]:

$$
J=\left(q N_{c} \mu\right) E \exp \left[\frac{-q\left(\varphi_{t}-\sqrt{q E / \pi \varepsilon_{r} \varepsilon_{0}}\right)}{k T}\right],
$$

где $J$ - плотность тока, $q-$ заряд электрона, $N_{c}$ - плотность состояний в зоне проводимости $\mathrm{SiO}_{x}$, $\mu$ - подвижность электронов, $E-$ напряженность электрического поля в диэлектрике, $\varphi_{t}-$ глубина залегания ловушки, $k-$ постоянная Больцмана, $T-$ абсолютная температура, $\varepsilon_{r}-$ относительная диэлектрическая проницаемость $\mathrm{SiO}_{x}$ на частоте $1 \mathrm{kHz}, \varepsilon_{0}$ - диэлектрическая проницаемость вакуума, дает значение для тангенса угла наклона зависимости $\ln J$ от $V^{1 / 2}$, близкое к характерному для эффекта Пула-Френкеля $\approx 4.7 \mathrm{~V}^{1 / 2}$.

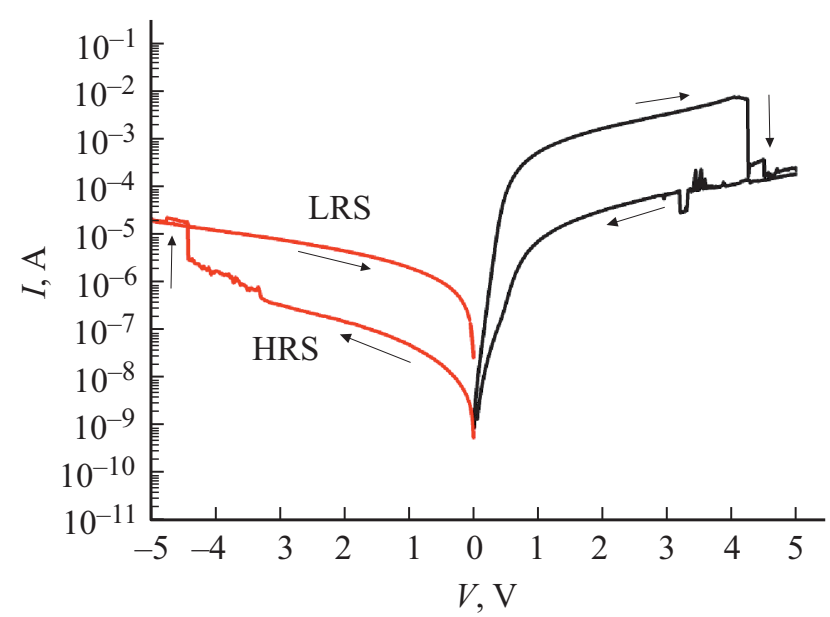

Рис. 3. ВАХ МОП-структуры со слоем $\mathrm{SiO}_{x}$, иллюстрирующая типичный вид биполярного РП анионного типа [19]. Скорость развертки $\beta \approx 0.3 \mathrm{~V} / \mathrm{s}$. Стрелками отмечено направление гистерезиса ВАХ при напряжениях $V>0$ и $V<0$. 
Значение $\varphi_{t}$, определяемое по формуле:

$$
\varphi_{t}=k T \ln \frac{J_{0}}{q \mu E N_{c}},
$$

составило $\approx 0.97 \mathrm{eV}$. Величина $J_{0}$ определялась в точке пересечения экстраполированной прямой $\lg J \sim E^{1 / 2} \mathrm{c}$ осью токов при $E=0$. Для значения произведения $\mu E$ бралась тепловая скорость электронов. Значение $N_{c}$ определялось, исходя из эффективной массы для электронов в $\mathrm{SiO}_{2} 0.4 m_{0}[21]\left(m_{0}-\right.$ масса свободного электрона).

При $V<0$ величина тока была меньше (кривая 2), чем при $V>0$ из-за наличия в полупроводнике слоя, обедненного электронами [15], на котором падала часть напряжения, приложенного к МОП-структуре. В этой области не наблюдалось эффекта Пула-Френкеля. Для резистивного переключения в исследованной структуре не требовалось проведения электроформовки. При достаточно больших напряжениях $V>0$ (кривая 2) происходило резкое уменьшение тока через МОП-структуру. Этот эффект можно объяснить перераспределением напряжения с полупроводника на диэлектрик, что приводило к эффекту разрушения проводящих нитей в диэлектрике (например, в виде уже образованных из-за неровности поверхности полупроводника филаментов [19], шунтирующих конденсатор) и уменьшению тока утечки через него. Усиление поля в диэлектрике в этом случае может быть связано с увеличением поверхностной емкости полупроводника из-за увеличения заряда поверхностных состояний (ПС) при обогащении поверхности электронами с ростом $V>0$ или, возможно, с образованием инверсного слоя в полупроводнике из-за отрицательного заряжения ПС. При некотором пороговом напряжении $V<0$ (кривая 3) оказывалось возможным возникновение новых проводящих нитей. Изменение силы тока при биполярном РП достигало двух порядков величины и было достаточно воспроизводимым. Следует особо подчеркнуть, что описанный эффект РП не наблюдался в аналогичных МОП-структурах без островков $\mathrm{GeSi}$.

Заметим, что эффект РП в исследованных МОП-структурах также проявлялся в изменении малосигнальных параметров эквивалентной цепи МОП-структуры. На рис. 4 приведены частотные зависимости малосигнальных параметров МОП-структуры с оксидным слоем $\mathrm{SiO}_{x}$. Анализ этих зависимостей показывает, что на низкой частоте (кривые 1-3) практически достигается насыщение максимальной емкости $C_{m}$, которая равна емкости диэлектрика. Оценка относительной диэлектрической проницаемости диэлектрика $\varepsilon$ по формуле для плоского конденсатора:

$$
\varepsilon=C_{m} d / \varepsilon_{0} S
$$

дает значение $\varepsilon \approx 10$, характерное для $\mathrm{SiO}_{x}$. Уменьшение емкости с ростом частоты обусловлено уменьшением емкости полупроводника. После РП в
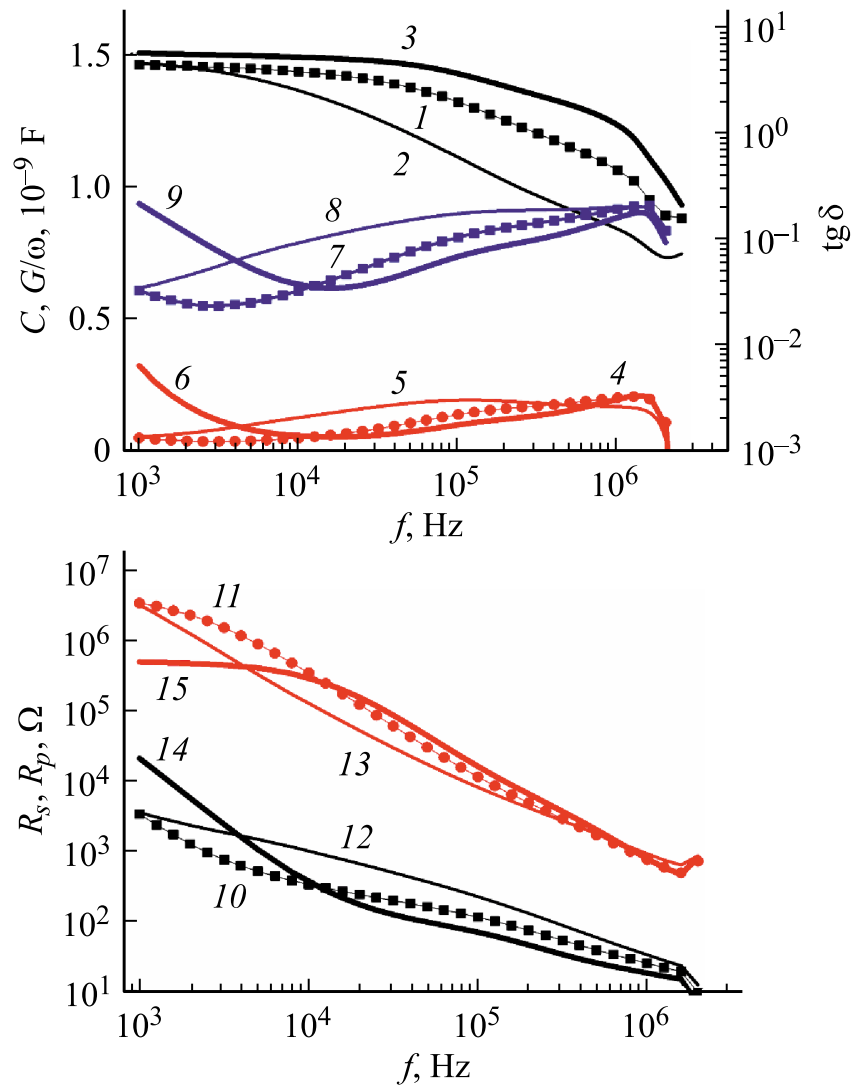

Рис. 4. Зависимости $C(1-3), G / \omega(4-6), \operatorname{tg} \delta$ (7-9), $R_{s}(10,12,14)$ и $R_{p}(11,13,15)$ от $f$ для МОП-структуры со слоем $\mathrm{SiO}_{x}$. Кривые $1,4,7,10,11-$ характеристики в исходном состоянии. Кривые 3, 6, 9, 14,15 - характеристики после РП при -6 V. Кривые 2, 5, 8, 12, 13 - после РП при $6 \mathrm{~V}$.

этой области величина емкости увеличивалась из-за накопления в диэлектрике положительного заряда при напряжении переключения $V_{p}<0$ (кривая 3) и уменьшалась из-за накопления в диэлектрике вблизи границы раздела диэлектрик-полупроводник отрицательного заряда при напряжении переключения $V_{p}>0$ (кривая 2). При этом наблюдался параллельный сдвиг ВФХ и ВСХ на частоте $100 \mathrm{kHz}$, соответствующий изменению напряжения плоских зон $V_{F B}$ на $+1 \mathrm{~V}$ $\left(V_{p}<0\right)$ и на $-1 \mathrm{~V}\left(V_{p}>0\right)$ относительно исходной характеристики (до переключения). Это значение соответствовало плотности встроенного заряда $N_{S S} \approx 10^{12} \mathrm{~cm}^{-2}$, рассчитанной по формуле [15]:

$$
N_{S S}=C_{m} V_{F B} / q S .
$$

Происхождение этого заряда в структуре объясняется перемещением ионов кислорода в филаментах при $V_{p}<0 \quad$ в области интерфейса диэлектрик-полупроводник в полупроводник и отдачей в него электронов. В результате этого процесса формируется канал переноса электронов между электродами по цепочке вакансий, образующих филамент. При $V_{p}>0$ происходит обратный процесс возврата ионов 
кислорода с заполнением кислородных вакансий в филаменте вблизи границы диэлектрик-полупроводник с образованием барьера для электронов и подавлением эффективного переноса электронов через филамент. Подобные механизмы, поясняющие термополевуюполевую деградацию МОП-структур, без учета образования филаментов были рассмотрены в работе [22]. Образование филаментов после приложения $V_{p}<0$ к структуре проявляется в возникновении участков омических потерь на кривых $G / \omega$ и $\operatorname{tg} \delta$ в области низких частот (кривые 6 и 9) [13]. После приложения $V_{p}>0$ к структуре омические потери на низких частотах практически исчезают (кривые 5 и 8 ). Омические потери имеют место и в исходном состоянии МОП-структуры (кривая 7), что объясняет проявление эффекта РП без предварительной электроформовки.

По зависимостям $G / \omega$ от $C$ (диаграммы Коула-Коула) [12] установлен сложный спектр ПС, который может быть описан несколькими релаксаторами. Этот спектр сужается с ростом обогащения поверхности полупроводника электронами при РП (можно построить диаграмму Коула-Коула по кривым 3 и 6), а также с ростом температуры. Оценка поверхностной плотности ПС по максимуму зависимости $G / \omega$ от частоты (кривая 5 ) дает значение $\sim 4 \cdot 10^{11} \mathrm{~cm}^{-2}$, а оценка энергии активации ПС по температурной зависимости указанного максимума методом [8] дает значение $\sim 0.39 \mathrm{eV}$.

Формирование и разрушение филаментов в процессе РП проявляется также в частотных зависимостях $R_{s}$ и $R_{p}$ (ср. кривые 14 и 15 и кривые 12 и 13 соответственно). С другой стороны, минимальное последовательное сопротивление на высокой частоте, которое определяется площадью металлических электродов, составляет $\sim 10 \Omega$ и практически не меняется при РП, что свидетельствует об отсутствии электрохимических процессов на границе раздела металлических электродов с диэлектриком при РП.

\section{3. Резистивное переключение в случае МОП-структур на основе СДЦ, влияние оптического излучения}

На рис. 5 приведены ВАХ МОП-структуры со слоем СДЦ. Анализ ВАХ показал, что механизм протекания тока через эту структуру трудно установить вследствие влияния области пространственного заряда (ОПЗ) на границе раздела диэлектрик-полупроводник и захвата носителей на ловушки. Однако в этих структурах также наблюдалось биполярное РП без предварительной электроформовки. При $V_{p}>0(5 \mathrm{~V})$ в темноте (кривая 1 ) происходило РП из исходного состояния в СВС с уменьшением тока на 4 порядка величины. При этом в СВС при уменьшении $V>0$ от $8 \mathrm{~V}$ ток уменьшался по экспоненциальному закону и при $V \sim 2.5 \mathrm{~V}$ менял знак. Это явление было ранее отмечено в [23] как электретный эффект, связанный с захватом электронов или

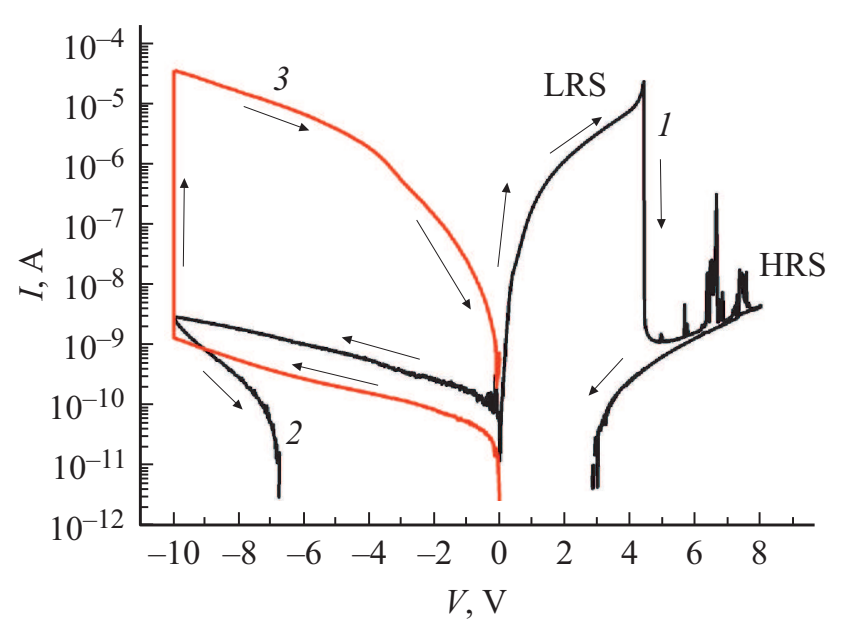

Рис. 5. ВАХ МОП-структуры со слоем СДЦ, иллюстрирующие типичный вид резистивного биполярного РП. Скорость развертки $\beta \approx 0.3 \mathrm{~V} / \mathrm{s}$. Стрелками отмечено направление гистерезиса ВАХ. Кривая 1 - переключение в СВС при $V>0$ в темноте, кривая $2-\mathrm{BAX}$ при $V<0$ в темноте, кривая $3-$ переключение в СНС при $V>0$ при освещении.

дырок на ловушки, локализованные в диэлектрике вблизи границ с металлическими электродами. Дальнейший ход ВАХ при уменьшении напряжения до $V=-10 \mathrm{~V}$ не показывает переключения в СНC (кривая 2), а гистерезис в ВАХ связан с ловушками и электретным эффектом. Однако переключение в СНС может быть достигнуто подсветкой образца излучением ЛД [3] с потоком квантов $10^{21} \mathrm{~cm}^{-2} \mathrm{~s}^{-1}$ (кривая 3). Переключение происходило при $V=-10 \mathrm{~V}$; значение тока через структуру восстанавливалось до значений, характерных для состояния до переключения в СВС при $V>0$. Влияние подсветки излучением ЛД на РП в МОП-структурах качественно можно объяснить перераспределением падения напряжения между слоем диэлектрика и ОПЗ в полупроводнике вследствие роста проводимости и емкости полупроводника при освещении [3]. При этом эффекту РП в МОП-структуре способствует наличие наноостровков $\mathrm{GeSi}$ на поверхности $\mathrm{Si}$, которые играют роль концентраторов электрического поля в диэлектрике: в аналогичных структурах без островков эффект РП не наблюдается.

Следует отметить, что наблюдаемое переключение требует меньших затрат энергии по сравнению с аналогичными мемристивными структурами МОМ с такой же площадью электродов [24].

Влияние освещения представляет интерес с точки зрения разработки мемристивных структур, чувствительных к свету, поэтому заслуживает детального изучения, как это сделано, например, для планарных фотомемристоров со структурой $\mathrm{Au} / \mathrm{MoS}_{2} / \mathrm{Au}$ [25]. Такое исследование планируется в дальнейшем и будет предметом отдельного сообщения. В настоящее время можно лишь констатировать, что секундное воздействие используемого лазера приводило к увеличению тока при 


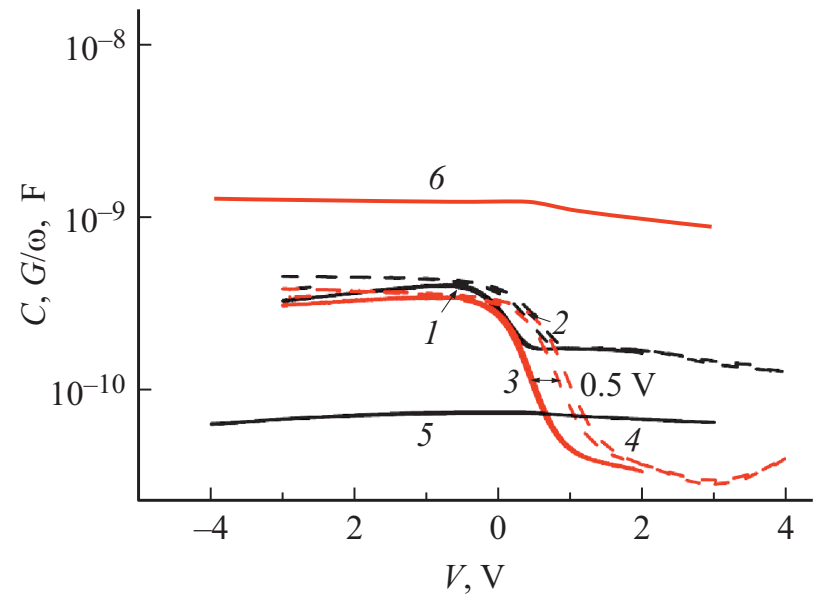

Рис. 6. Зависимости малосигнальных емкости $C(1,2,5)$ и приведенной к круговой частоте проводимости $G / \omega(3,4,6)$ в параллельной схеме замещения МОП-структуры со слоем СДЦ на тестирующей частоте $20 \mathrm{kHz}$. Кривые 1,3 - в исходном состоянии; кривые $2,4-$ после РП в темноте при $5 \mathrm{~V}$; кривые 5, 6 - после РП при освещении при $-15 \mathrm{~V}$.

переключении почти на 5 порядков величины, в то время как в [25] сообщается об изменении тока при освещении на 1 порядок величины.

Зависимости малосигнальных параметров эквивалентной схемы МОП-структуры с диэлектрическим слоем СДЦ от напряжения и частоты в исходном состоянии и после РП приведены на рис. 6 и 7. Из рис. 6 видно, что в исходном состоянии и после РП при $5 \mathrm{~V}$ ВФХ (кривые 1 u 2) имеют ступенчатую форму, характерную для высокочастотной емкости. После РП происходит параллельный сдвиг кривых по оси напряжений на $0.5 \mathrm{~V}$ в область положительных величин. Этот результат можно объяснить зарядкой диэлектрика отрицательным зарядом, инжектированным из полупроводника. Зависимость проводимости от напряжения также имеет ступенчатый вид и также смещается в сторону положительных напряжений при РП (кривые 3,4 ) на $\sim 0.5 \mathrm{~V}$. Оценка $N_{S S}$ по формуле (5) для МОП-структуры со слоем СДЦ дает небольшое изменение $N_{S S}$ при РП $\approx 1.4 \cdot 10^{11} \mathrm{~cm}^{-2}$. После РП при $-15 \mathrm{~V}$ после выключения освещения емкость уменьшается (кривая 5) до практически не зависящей от напряжения величины, а проводимость возрастает (кривая 6) более чем на порядок величины, при этом значение проводимости также слабо зависит от напряжения. Данный эффект обусловлен накоплением положительного заряда в диэлектрике (оценка его плотности дает значение более $10^{13} \mathrm{~cm}^{-2}$ ) и достижением емкости, которая характерна для обедненного слоя в полупроводнике и значительно меньше емкости диэлектрика. Увеличение проводимости (кривая 6) обусловлено возникновением филаментов, шунтирующих диэлектрик.

Механизм образования филаментов в целом аналогичен описанному выше для МОП-структуры с диэлектрическим слоем $\mathrm{SiO}_{x}$. Однако в МОП-структурах с диэлектрическим слоем СДЦ переключение из СВС в СНС наблюдалось только при подсветке, роль которой состоит в перераспределении напряжения между ОПЗ в полупроводнике и диэлектрике, так, что напряженность электрического поля в СДЦ становится достаточной для роста филаментов.

На рис. 7 показаны частотные зависимости малосигнальных параметров эквивалентной схемы МОП-структуры на основе СДЦ. Следует отметить, что эти параметры относительно слабо меняются в разных состояниях (кривые $1-3)$, так как при малых напряжениях слабо меняются стационарные токи после РП, как видно из BAX (рис. 5). Однако из частотных зависимостей этих характеристик можно получить важную информацию об электронных явлениях в МОП-структуре на базе СДЦ до и после РП. В указанных зависимостях не достигается максимальная емкость на низкой частоте вследствие влияния емкости ОПЗ. Емкость при $-10 \mathrm{~V}$ в темноте на частоте $10^{3} \mathrm{~Hz}$ уменьшается после РП в 6 раз (ср. кривые 2 и 1,3 на рис. 7) по этой же причине. Частотные зависимости $G / \omega$ (кривые $5-8)$ с максимумом на
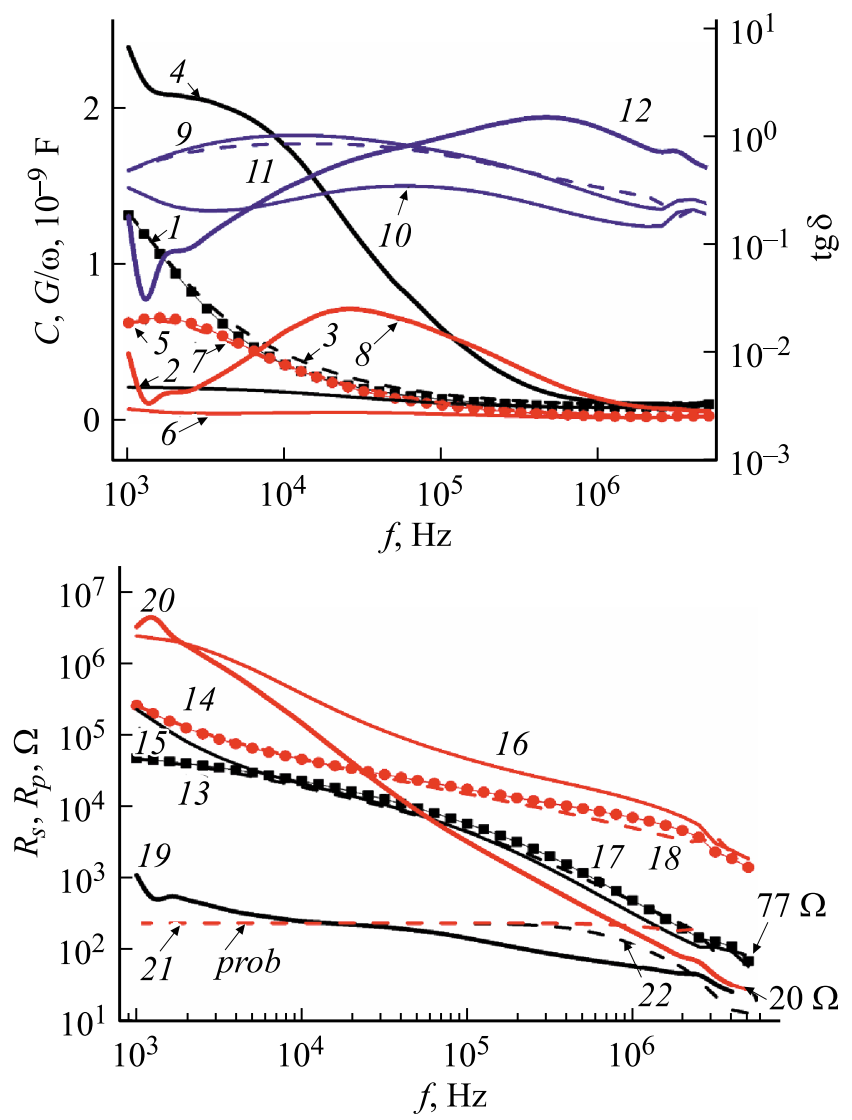

Рис. 7. Зависимости $C(1-4), G / \omega(5-8), \operatorname{tg} \delta(9-12)$, $R_{s}(13-17)$ и $R_{p}(18-22)$ от $f$ для МОП- структуры со слоем СДЦ. Кривые $1,5,8,13,14$ - характеристики в исходном состоянии. Кривые 2, 6, 10, 15, 16 - характеристики после РП при -10 V. Кривые 3, 7, 11, 17, 18 - характеристики после РП при $5 \mathrm{~V}$. Кривые 4,8,12,19,20 - характеристики после РП при $-10 \mathrm{~V}$ при освещении. Кривые 21,22 - характеристики после пробоя на свету при $-15 \mathrm{~V}$. 


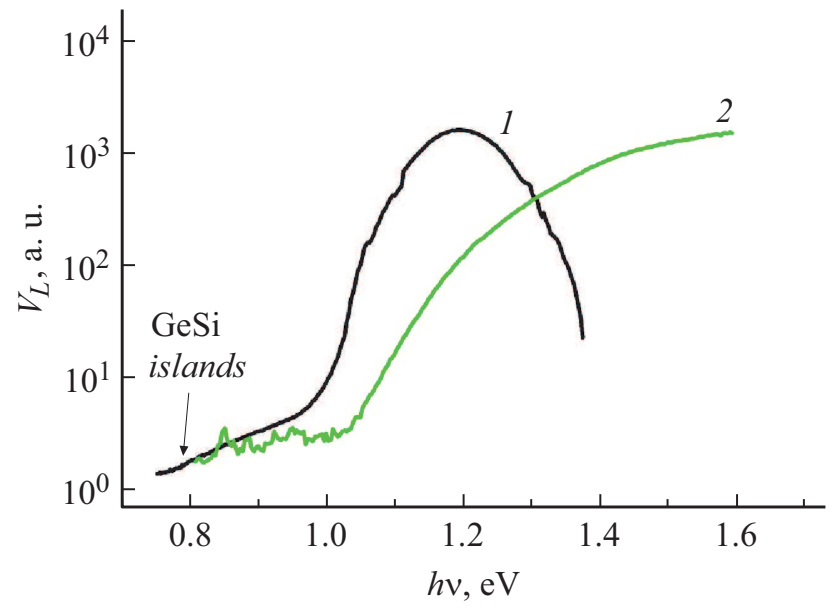

Рис. 8. Спектральные зависимости малосигнальной фото-ЭДС $V_{L}$ для МОП-структуры со слоем СДЦ. Кривая $1-$ в СВС, кривая $2-$ в СНC.

определенной частоте $G_{m} / \omega$ определяются плотностью ПС, а время, соответствующее максимуму зависимости $G / \omega$ от частоты:

$$
\tau=\frac{1}{2 \pi f_{m}},
$$

является временем релаксации ловушек, локализованных на поверхности полупроводника (ПС) или в диэлектрике вблизи границы раздела диэлектрик-полупроводник. Зависимости $G / \omega$ от $C$ удовлетворительно описываются кривыми Коула-Коула, что характерно для одного типа релаксаторов [8]. По температурной зависимости $\tau$ [8] была определена энергия активации ПС, которая была практически одинаковой в СНС и в CВС и составляла $\approx 0.52 \mathrm{eV}$. Учитывая, что фото-ЭДС насыщения для МОП-структур с диэлектрическим слоем СДЦ составляла $0.42 \mathrm{~V}$, а положение уровня Ферми $E_{F}-E_{V} \approx 0.1 \mathrm{eV}$, то в температурной зависимости времени релаксации преобладал выброс носителей с уровня $E_{S}-E_{V} \approx 0.52 \mathrm{eV}$. По величине проводимости в максимуме $G_{p m} / \omega$ была сделана оценка плотности поверхностных состояний $N_{S S}$. Значения $G_{p m} / \omega$ рассчитывались по эквивалентной схеме, учитывающей емкость диэлектрика $C_{D}$, по формуле [8]:

$$
G_{p m} / \omega=\left(G_{m} / \omega\right) /\left[\left(G_{m} / \omega C_{D}\right)^{2}+\left(1-C / C_{D}\right)^{2}\right],
$$

где $C$ - емкость, соответствующая максимуму $G_{m} / \omega$. Потери в диэлектрике не учитывались ввиду их малости. Для определения величины $N_{S S}$ использовалась формула

$$
2 G / \omega_{p m} S=q^{2} N_{S S} / 4 k T .
$$

Полученные значения $N_{S S}=(3-5) \cdot 10^{11} \mathrm{~cm}^{-2}$ для разных образцов были приблизительно одинаковыми в CHC и СВС и практически не зависели от интенсивности освещения и от температуры. Это означает, что в процессе РП изменяется только сопротивление диэлектрика и величина встроенного заряда в нем. При переключении МОП-структуры из СВС в СНС при отрицательном напряжении положительный встроенный заряд образовывался в диэлектрике вследствие ухода электронов с ловушек, локализованных в диэлектрике вблизи границы диэлектрик-полупроводник в квазинейтральную область $n-\mathrm{Si}$. При обратном переключении из СНC в СВС (при положительном напряжении) происходил обратный процесс, связанный с окислением избыточного $\mathrm{Zr}$ в СДЦ и разрывом филаментов вблизи границы диэлектрик-полупроводник.

Частотные зависимости $\operatorname{tg} \delta$ (кривые 9-12) свидетельствовали о потерях в МОП-структурах с оксидным слоем СДЦ, связанных с перезарядкой ПС (максимум, связанный с данными потерями, наблюдался на всех кривых и соответствовал наличию максимумов на частотных зависимостях $G / \omega)$. Переключение из СВС в СНC при напряжении $-10 \mathrm{~V}$ приводило к появлению омических потерь на низких частотах (кривая 10) вследствие образования филаментов. К такому же результату приводила подсветка образца (кривая 12) вследствие увеличения тока утечки через диэлектрик. В целом потери оставались незначительными вследствие падения большей части приложенного к МОП-структуре напряжения на ОПЗ вблизи границы диэлектрик-полупроводник как в исходном состоянии, так и после переключения из СВС в СНС и обратно.

Величина последовательного сопротивления $R s \propto$ на высокой частоте $f=5 \cdot 10^{6} \mathrm{~Hz}$ МОП-структур с оксидным слоем СДЦ (кривые $13,15,17$ ) была невелика $(\sim 77 \Omega)$ и определялась суммарным сопротивлением металлического электрода и полупроводниковой подложки. Освещение или переключение в СНС уменьшали $R_{s \infty}$ до $\sim 20 \Omega$ (кривые 19,21$)$. Данные значения $R_{s \infty}$ соответствовали сопротивлению МОМ-структуры с аналогичными параметрами слоя диэлектрика и размерами верхнего электрода. Быстродействие МОП-структур при считывании малым сигналом не определялось произведением $C_{D} R_{s \infty}[26]$, которое должно было составлять $\sim\left(10^{-7}-10^{-8}\right) \mathrm{s}$. В действительности быстродействие МОП-структур определялось временем перезарядки ПС в соответствии с формулой (6). В исходном состоянии и при РП в темноте время перезарядки ПС составляло $\sim 10^{-4} \mathrm{~s}$, а при освещении уменьшалось до $10^{-8} \mathrm{~s}$. Параллельное сопротивление (кривые 14, 16, 18, 20) слабо зависело от состояния МОП-структуры со слоем СДЦ вследствие влияния ОПЗ в полупроводнике. Для параллельного сопротивления характерны относительно высокие значения $\left(3 \cdot 10^{5}-3 \cdot 10^{6} \Omega\right)$, особенно на низкой частоте $\left(\sim 10^{3} \mathrm{~Hz}\right)$. Переключение из СВС в СНС приводило к резкому уменьшению параллельного сопротивления до значений $\sim 250 \Omega$, соответствующих значению $R_{s}$, и отсутствию частотной зависимости вплоть до высоких частот (почти до $10^{6} \mathrm{~Hz}$ ) (однако сопротивление МОП-структуры в СНС оставалось нелинейным, что связано с влиянием потенциального барьера на границе раздела диэлектрик-полупроводник. 
Наличие указанного барьера приводило, в частности, к возникновении фото-ЭДС при освещении. На рис. 8 приведены малосигнальные спектры фото-ЭДС $V_{L}(h v)$ ( $h v-$ энергия квантов фотовозбуждения) для МОП-структур со слоем СДЦ до и после переключения из СВС в СНC (кривые 1 и 2 соответственно). Стрелкой обозначен край полосы фоточувствительности, связанной с межзонным оптическим поглощением в островках $\mathrm{GeSi}(\sim 0.8 \mathrm{eV})$. Значение фоточувствительности в данной спектральной области остается практически неизменным после РП.

В спектральной области собственной фоточувствительности Si МОП-структуры в СВС (кривая 1) наблюдается ее уменьшение с ростом $h v$ в коротковолновой части спектра, связанное с рекомбинацией фотовозбужденных носителей заряда на ПС на границе диэлектрик-полупроводник. В СНС фоточувствительность МОП-структуры в спектральной области собственной фоточувствительности $\mathrm{Si}$ возрастает с ростом $h v$ (кривая 2), что связано с влиянием филаментов, пронизывающих диэлектрик и тем самым обеспечивающих электрический контакт между слоем наноостровков $\mathrm{GeSi} / \mathrm{Si}(001)$ и металлическим электродом. В связи с этим рекомбинация на ПС оказывает меньшее влияние на спектр фоточувствительности МОП-структуры, находящейся в $\mathrm{CHC}$, чем в случае $\mathrm{CBC}$.

\section{Заключение}

Показано, что встраивание самоформирующихся наноостровков $\mathrm{GeSi} / \mathrm{Si}(001)$ на границе раздела диэлектрик-полупроводник в МОП-структурах на основе $n^{+}-\mathrm{Si}(001)$ с диэлектрическими слоями $\mathrm{SiO}_{x}$ и $\mathrm{ZrO}_{2}(\mathrm{Y})$, полученными методом магнетронного распыления, приводит к появлению биполярного резистивного переключения в диэлектрике без предварительной электроформовки. Переключение обусловлено образованием и гибелью проводящих филаментов в диэлектрике в зависимости от полярности переключающего напряжения, при этом наноостровки GeSi служат концентраторами электрического поля в диэлектрике, инициируя формирование филаментов. Исследованы частотные и температурные зависимости малосигнальных параметров эквивалентной схемы МОП-структур и их изменение при резистивном переключении. Установлено, что переключение МОП-структур в высокоомное состояние при отрицательном напряжении на металлическом электроде сопровождается накоплением встроенного положительного заряда на ловушках в диэлектрике вблизи границы раздела диэлектрик-полупроводник, предположительно кислородных вакансий, выстраивающихся в филаменты под действием внешнего электрического поля. Обратное переключение сопровождается накоплением отрицательного заряда вблизи границы раздела диэлектрик-полупроводник, что свидетельствует об образовании ловушек для электронов и об окислении филаментов.
Обнаружено, что излучение лазерного диода с длиной волны $660 \mathrm{~nm}$ стимулирует резистивное переключение в МОП-структуре с диэлектрическим слоем $\mathrm{ZrO}_{2}(\mathrm{Y})$ из высокоомного в низкоомное состояние. Эффект связан с увеличением проводимости области пространственного заряда вблизи границы раздела диэлектрик-полупроводник вследствие генерации избыточных носителей заряда при межзонном оптическом поглощении в $\mathrm{Si}$ (эффект фотопроводимости), что вызывает перераспределение внешнего переключающего напряжения с области пространственного заряда на диэлектрик.

Также обнаружено различие в форме спектров малосигнальной фото-ЭДС МОП-структур в спектральной области собственной фоточувствительности $\mathrm{Si}$ в высокоомном и низкомном состояниях, связанных с доминированием рекомбинации фотовозбужденных носителей заряда на поверхностных состояниях на границе раздела диэлектрик-полупроводник в первом случае и утечкой фотовозбужденных носителей через филаменты на металлический электрод - во втором.

Обнаруженные в работе особенности резистивного переключения, связанные со свойствами полупроводниковой подложки, расширяют возможности его использования.

\section{Финансирование работы}

Работа выполнена в рамках грантов Российского фонда фундаментальных исследований № 18-29-23001 (в части оптимизации металл-оксидных мемристивных структур) и № 19-29-03026 (в части использования эпитаксиальных структур $\mathrm{SiGe})$.

\section{Конфликт интересов}

Авторы заявляют, что у них нет конфликта интересов.

\section{Список литературы}

[1] Resistive switching: from fundamentals of nanoionic redox processes to memristive device applications / Eds D. Ielmini, R. Waser. Weinheim: Wiley-VCH, 2016. 784 p.

[2] Merrikh Bayat F., Prezioso M., Chakrabarti B., Nili H., Kataeva I., Strukov D. // Nature Commun. 2018. Vol. 9. P. 2331. DOI: $10.1038 / \mathrm{s} 41467-018-04482-4$

[3] Тихов С.В., Горшков О.Н., Коряжкина М.Н., Антонов И.Н., Касаткин А.П. // Письма в ЖТФ. 2016. T. 42. Вып. 10. C.78-84. [Tikhov S.V., Gorshkov O.N., Koryazhkina M.N., Antonov I.N., Kasatkin A.P. // Tech. Phys. Lett. 2016. Vol. 42. N 5. P. 536-538. DOI $10.1134 / \mathrm{S} 1063785016050308]$

[4] Тихов С.В., Горшков О.Н., Антонов И.Н., Касаткин А.П., Коряжккина М.Н. // Письма в ЖТФ. 2014. Т. 40. Вып. 19. C. 18-26. Tikhov S.V., Gorshkov O.N., Antonov I.N., Kasatkin A.P., Koryazhkina M.N. // Tech. Phys. Lett. 2014. Vol. 40. N 10. P. 837-840.

DOI: $10.1134 / \mathrm{S} 1063785014100137]$ 
[5] Тихов С.В., Горшков О.Н., Антонов И.Н., Касаткин А.П., Коряжкина М.Н., Шарапов А.Н. Способ определения электрофизических параметров конденсаторной структуры мемристора, характеризующих процесс формовки. Патент № 2585963 от 11.05.2016.

[6] Ielmini D. // Semicond. Sci. Technol. 2016. Vol. 31. P. 063002 (25 p). DOI: $10.1088 / 0268-1242 / 31 / 6 / 063002$

[7] Филатов Д.О., Карзанов В.В., Антонов И.Н., Гориков О.Н. // Письма в ЖТФ. 2018. Т. 44. Вып. 24. С. 88-93. [Filatov D.O., Karzanov V.V., Antonov I.N., Gorshkov O.N. // Tech. Phys. Lett. 2018. Vol. 44. N 12. P. 1160-1162. DOI: $10.1134 / \mathrm{S} 1063785018120416]$

[8] Тихов С.В., Горшков О.Н., Коряжкина М.Н., Касаткин А.П., Антонов И.Н., Вихрова О.В., Морозов А.И. // ФТП. 2016. Т. 50. Вып. 12. С. 1615-1619. [Tikhov S.V., Gorshkov O.N., Koryazhkina M.N., Kasatkin A.P., Antonov I.N., Vihrova O.V., Morozov A.I. // Semiconductors. 2016. Vol. 50. N 12. P. 1589-1594.

DOI: $10.1134 / \mathrm{S} 1063782616120228]$

[9] Филатов Д.О., Круглова М.В., Исаков М.А., Сипрова С.В., Марычев М.О., Шенгуров В.Г., Чалков В.Ю., Денисов С.А. // ФТП. 2008. Т. 42. Вып. 9. C. 1116-1121. [Filatov D.O., Kruglova M.V., Isakov M.A., Siprova S.V., Marychev M.O., Shengurov V.G., Chalkov V.Yu., Denisov S.A. // Semiconductors. 2008. Vol. 42. N 9. P. 1098-1103. DOI: $10.1134 / \mathrm{S} 1063782608090169]$

[10] Светлов С.П., Шенгуров В.Г., Чалков В.Ю., Красильник З.Ф, Андреев Б.А., Дроздов Ю.Н. // Изв. РАН. Сер. Физ. 2001. Т. 65. Вып. 2. С. 204-207.

[11] Якимов А.И., Двуреченский А.В., Кириенко В.В., Никифоров А.И. // ФТТ. 2005. Т. 47. Вып. 1. С. 37-40. [Yakimov A.I., Dvurechenski A.V., Kirienko V.V., Nikiforov A.I. // Phys. Solid State. 2005. Vol. 47. N 1. P. 34-37. DOI: 10.1134/1.1853439]

[12] Орешкин П.Т. Физика полупроводников и диэлектриков. М.: Высшая школа, 1977. 448 с.

[13] Тихов С.В., Горшков О.Н., Антонов И.Н., Касаткин А.П., Королев Д.С., Белов А.И., Михайлов А.Н., Тетельба$y_{м}$ Д.И. // ЖТФ. 2016. Т. 86. Вып. 5. С. 107-111. [Tikhov S.V., Gorshkov O.N., Antonov I.N., Kasatkin A.P., Korolev D.S., Belov A.I., Mikhaylov A.N., Tetelbaum D.I. // Tech. Phys. 2016. Vol. 61. N 5. P. 745-749.

DOI: $10.1134 / \mathrm{S} 106378421605025 \mathrm{X}]$

[14] Тихов С.В. // ФТП. 2012. Т. 46. Вып. 10. С. 1297-1303. [Tikhov S.V. // Semiconductors. 2012. Vol. 46. N 10. P. 1274-1280. DOI: $10.1134 / \mathrm{S} 1063782612100144]$

[15] Овсюк В.Н. Электронные процессы в полупроводниках с областями пространственного заряда. Новосибирск: Наука, 1984. $252 \mathrm{c}$.

[16] Захаров А.К., Неизвестный И.Г., Овсюк В.Н. В кн.: Свойства структур металл-диэлектрик-полупроводник / Под ред. А.В. Ржанова. М.: Наука, 1976. С. 47-97.

[17] Mikhaylov A.N., Belov A.I., Guseinov D.V., Korolev D.S., Antonov I.N., Efimovykh D.V., Tikhov S.V., Kasatkin A.P., Gorshkov O.N., Tetelbaum D.I., Bobrov A.I., Malekhonova N.V., Pavlov D.A., Gryaznov E.G., Yatmanov A.P. // Mat. Sci. Eng. B. 2015. Vol. 194. P. 48-54. DOI: 10.1016/j.mseb.2014.12.029
[18] Mikhaylov A.N., Gryaznov E.G., Belov A.I., Korolev D.S., Sharapov A.N., Guseinov D.V., Tetelbaum D.I., Tikhov S.V., Malekhonova N.V., Bobrov A.I., Pavlov D.A., Gerasimova S.A., Kazantsev V.B., Agudov N.V., Dubkov A.A., Rosário C.M.M., Sobolev N.A., Spagnolo B. // Phys. Stat. Sol. C. 2016. Vol. 13. P. 870-881.

DOI: $10.1002 /$ pssc. 201600083

[19] Sun W., Gao B., Chi M., Xia Q., Yang J.J., Qian H., Wu H. // Nat. Commun. 2019. Vol. 10. P. 3453.

DOI: $10.1038 / \mathrm{s} 41467-019-11411-6$

[20] Fu-Chien Chiu, Zhi-Hong Lin, Che-Wei Chang, Chen-Chih Wang, Kun-Fu Chuang, Chih- Yao Huang, Joseph Ya-min Lee, Huey-Liang Hwang // J. Appl. Phys. 2005. Vol. 97. P. 034506. DOI: 10.1063/1.1846131

[21] Некрашевич С.С., Гриценко В.А. // ФТТ. 2014. Т. 56. Вып. 2. C. 209-223. [Nekrashevich S.S., Gritsenko V.A. // Phys. Solid State. 2014. Vol. 56. N 2. P. 207-222. DOI: $10.1134 / \mathrm{S} 106378341402022 \mathrm{X}]$

[22] Барабан А.П., Булавинов В.В., Коноров П.П. Электроника слоев $\mathrm{SiO}_{2}$ на кремнии. Л.: Изд-во ЛГУ, 1988. 302 с.

[23] Тихов С.В., Горшков О.Н., Белов А.И., Антонов И.Н., Морозов А.И., Коряжккина М.Н., Михайлов А.Н. // ЖТФ. 2019. T. 89. Вып. 6. C. 933-940. [Tikhov S.V., Gorshkov O.N., Belov A.I., Antonov I.N., Morozov A.I., Koryazhkina M.N., Mikhaylov A.N. // Tech. Phys. 2019. Vol. 64. N 6. P.873-880. DOI: $10.1134 / \mathrm{S} 1063784219060227]$

[24] Горшков О.Н., Антонов И.Н., Белов А.И., Касаткин А.П., Михайлов А.Н. // Письма в ЖТФ. 2014. Т. 40. Вып. 3. C.12-19. [Gorshkov O.N., Antonov I.N., Belov A.I., Kasatkin A.P., Mikhaylov A.N. // Tech. Phys. Lett. 2014. Vol. 40. N 2. P.101-103. DOI: 10.1134/S1063785014020084]

[25] Wang W., Panin G.N., Fu X., Zhang L., Ilanchezhiyan P., Pelenovich V.O., Fu D., Kang T.W. // Scientific Reports. 2016. Vol. 6. N 1. P. 1-11. DOI: $10.1038 /$ srep31224

[26] Тихов С.В., Горшков О.Н., Антонов И.Н., Тетельбаум Д.И., Михайлов А.Н., Белов А.И., Морозов А.И., Karakolis P., Dimitrakis P. // ФТП. 2018. Т. 52. Вып. 12. C. 1436-1442. DOI: 10.21883/FTP.2018.12.46753.32 [Tikhov S.V., Gorshkov O.N., Antonov I.N., Tetelbaum D.I., Mikhaylov A.N., Belov A.I., Morozov A.I., Karakolis P., Dimitrakis P. // Semiconductors. 2018. Vol. 52. N 12. P. 1540-1546. DOI: 10.1134/S1063782618120242] 